\title{
A thermo-hydro-mechanical constitutive model and its numerical modelling for unsaturated soils
}

\author{
Wenhua $\mathrm{Wu}^{\text {a }}$, Xikui Li ${ }^{\mathrm{a}, *}, \mathrm{R}$. Charlier ${ }^{\mathrm{b}}, \mathrm{F}$. Collin ${ }^{\mathrm{b}}$ \\ ${ }^{a}$ The State key Laboratory for Structural Analysis of Industrial Equipment, Dalian University of Technology, Dalian 116024, PR China \\ ${ }^{\mathrm{b}}$ Département d'Infrastructures et de Géomécanique, Institut de Mécanique et Génie Civil, Université de Liège 4000 Liège - Sart Tilman, Belgium
}

Received 14 September 2001; received in revised form 15 January 2003; accepted 12 September 2003

\begin{abstract}
A thermo-hydro-mechanical (THM) constitutive model for unsaturated soils is proposed in this paper based on the existing models. The influences of temperature on the hydro-mechanical behaviour in unsaturated soils are described in the model. Particularly, the thermal softening phenomenon, i.e. decreases in value of the pre-consolidation pressure and in critical value of the suction of the SI (suction increasing) curve with heating process, is quantitatively modelled by using the experimental data and previous work [J. Geotech. Eng. ASCE 116 (12) (1990) 1765; J. Geotech. Eng. ASCE 116 (12) (1990) 1778; Can. Geotech. J. 25 (1988) 807; Int. J. Numer. Anal. Meth. Geomech. 22 (1998) 549; Can. Geotech. J. 37 (2000) 607; Characterisation and thermohydro-mechanical behaviour of unsaturated Boom clay: an experimental study. Thesis Doctoral 1999, Technical University of Catalonia (UPC), Barcelona, Spain]. Numerical modelling of the proposed THM model has also been implemented within the finite element code LAGACOM. Finally, the comparisons of the results obtained from the numerical modelling of the constitutive behaviour with existing experimental results show that the present model can simulate the thermo-hydro-mechanical behaviour in unsaturated soils with satisfaction. Some other numerical results given in the paper also validate the versatility and applicability of the present constitutive model.
\end{abstract}

(C) 2004 Elsevier Ltd. All rights reserved.

Keywords: Thermo-hydro-mechanical behaviour; Constitutive model; Numerical modelling; Unsaturated soils

\section{Introduction}

In recently years, the thermo-hydro-mechanical behaviour of unsaturated soils has attracted comprehensive attentions in engineering practice especially in nuclear waste disposal. It has been well known for a long time that the hydro-mechanical characteristics of porous media are much effected by the variation of temperature. Many efforts have been devoted to make deep understanding of the behaviour in different aspects.

One of the important aspects for quantitative study of coupled, transient THM behaviour in porous media is to establish the THM mathematical model. It composed of to analyze the mechanisms governing the THM behaviour and its evolution, to formulate the partial differential governing equations and to discretise the

\footnotetext{
${ }^{*}$ Corresponding author. Tel./fax: +86-411-4709186.

E-mail address: xikuili@dlut.edu.cn (X. Li).
}

governing equation system for numerical solutions of the initial-boundary value problems in hands. Lewis et al. [7-9] developed the finite element model and its solution procedure for heat transfer coupled with nonlinear hydro-mechanical process in saturated and unsaturated porous media. Thomas et al. [10-13] presented a fully coupled THM mathematical model based on the experimental results and previous work they achieved. They devoted much efforts on numerical modelling of coupled THM processes in porous media and its applications to environmental engineering problems, particularly to the numerical simulation of the THM behaviour in engineered clay barriers. Schrefler et al. [14-16] presented a general mathematical model for the analysis of THM problems in unsaturated soils with possible pollutant transport. In addition, they extended the application of the model to the numerical analysis for THM behaviour and damage phenomena of concrete at high temperature in fire resistance engineering. 
Furthermore, there are some other research groups devoting their efforts in mathematical modelling. Among them are Delage et al., Alonso and Gens et al., Pande et al., Rajapakse et al.

Another important aspect in study of the THM behaviour is to establish the constitutive model describing the coupled behaviour and its evolution and to develop the consistent algorithm for its implementation in the framework of thermodynamics combined with the internal state variable theory. Because of complexities of the THM behaviours in the porous media, it brings many difficulties for the establishment of THM constitutive model. The present paper will focus on the latter aspect for unsaturated soils.

In the experimental study, Gray [17] performed isothermal oedometer tests at different temperatures and revealed the dependence of the compressibility and the pre-consolidation pressure of unsaturated soils on temperature. Campanella and Mitchell [18] proceeded a detailed study on the thermal dilation of the soil constituents. Habibagahi [19] fulfilled isothermal consolidation tests at various temperatures and concluded that the permeability increases with increasing temperature due to the decrease in water viscosity. Numerous experiments indicated that the volumetric strain due to heating in soil samples under the drained condition depends on the over-consolidation ratio [20-22]. As temperature increases, the normal consolidated soil exhibits an irreversible contraction, which is opposite to the reversible expansion in the over-consolidated state. Hueckel and Borsetto [1] presented an expression to describe this behaviour. Morin and Silva [23], Mitchell [24] and Towhata et al. [25] tried to explain the thermal soften phenomenon from view of the double-layer theory [23] relating to temperature variation. When temperature increases, the thickness of the bound water layer reduces as water molecules are expelled, and clay particles can get closer one to another, resulting in an irreversible volume decrease. Delage et al. [26] investigated the thermal consolidation of Boom clay. As the results, they obtained the relation between water permeability and temperature in porous media and reproduced the thermal consolidation behaviour in laboratory tests.

The experimental study on the constitutive relationship to quantitatively describe the thermo-hydromechanical behaviour is another the most important aspects. In 1990, Hueckel et al. [1,2] proposed an extension of the modified Cam-Clay model for saturated soils to the model including the effects of temperature. Cui et al. [5] proposed a thermo-mechanical model for saturated clays based on the Cam-Clay model. Alonso et al. [27] Alonso and Gens [28] made great contributions on the experimental study for constitutive modelling of unsaturated soils. They extended the modified Cam-Clay model to integrate the effects of suction into the model and to present the well-known Alonso-Gens model for unsaturated soils. In recent years, they extended their work to include the coupled effect of temperature with hydro-mechanical behaviour into the model. Many experimental results used in this paper are collected from the doctoral thesis [6] working at the Alonso-Gens research group.

But there have been few work carried out for the development of the THM constitutive model for unsaturated soils. Gens [29] presented a constitutive model for unsaturated soils based on a generalisation of the Cam-Clay yield surface in the stress, suction and temperature space. A prospective version of the LTVP model for unsaturated soils is proposed by Modaressi and Modaressi [30]. Due to lack of relevant experimental results, the effects of temperature on suction and its related parameters were neglected in his model. In addition, the thermal yielding phenomenon described by critical thermal yield curve is also not taken into account. In this paper, a new fully thermo-hydromechanical constitutive model for unsaturated soils is proposed as an extension of the thermo-hydromechanical constitutive models previously presented by Hueckel et al. [1,2] and Cui et al. [5] for saturated soils to unsaturated ones. The model is established on the basis of the experimental results [1-6] for different types of soils, with particular attention given to volumetric strain change and the preconsolidation pressure variation with respect to temperature. The coupling behaviour between suction and temperature is also considered as one of important aspects in the model. As the present model consists of quintuple yield surfaces, the particular attention should be paid to the determination of the plastic strain increments. A consistent integration algorithm for the model with non-smooth quintuple yield surfaces, which is composed of the backward Euler return mapping algorithm for integration of the rate constitutive equations and the consistent elasto-plastic tangent modulus matrix, is developed. An iterative integration procedure with determination and readjustment of the active yield surfaces on the basis of the Kuhn-Tucker conditions is derived. The derived algorithm for constitutive modelling has been implemented in the FE code LAGACOM. The numerical results are illustrated in the last section to verify the presented model through the comparisons with the experimental results. Some results are further given to demonstrate capability and performance of the model.

\section{Principal experimental results concerning thermo- hydro-mechanical behaviours}

\subsection{The effects of temperature on hydraulic properties}

The water in the porous medium can be classified into two different types depending on the dimension of pore 
space and its interaction with the soil matrix: interaggregate water (bulk water or free water which can flow in the normal condition) and intra-aggregate water (weakly bonded diffuse-layer water and strongly bonded crystal water). The inter-aggregate water is distinguished from the intra-aggregate water mainly according to the pore water velocity. Namely, adsorbed water cannot flow under normal thermal condition, whereas the bulk water is mobile due to water pressure gradients in space. However, part of the adsorbed water will be converted to the bulk water with the development of temperature.

\subsubsection{The effects of temperature on the retention curves}

As shown by the experimental results, the retention curves shift as a whole towards the left side in the suction-saturation plot under increasing temperatures [6]. It implies that the suction decreases with increasing temperature under constant degree of saturation. The sensitivity of the suction with temperature change at certain constant value of the water content $w$ can be expressed by

$\left(\frac{\partial s(w)}{\partial T}\right)=\frac{s(w)}{a_{1}+b_{1} T}$,

where $T$ is temperature, $s$ suction. $a_{1}$ and $b_{1}$ are empirical functions depending on $w$ (or simply the coefficients). An explicit form to predict the suction development can then be obtained as below

$\frac{s(w, T)}{s\left(w, T_{\mathrm{r}}\right)}=\left(\frac{a_{1}(w)+b_{1}(w) T}{a_{1}(w)+b_{1}(w) T_{\mathrm{r}}}\right)^{b_{1}(w)}=\left(\frac{a_{1}+b_{1} T}{a_{1}+b_{1} T_{\mathrm{r}}}\right)^{b_{1}}$,

where $T_{\mathrm{r}}$ is the reference temperature. It is noted that temperature is not the unique factor affecting the suction variation, especially at the high suction state. Further research work is required to improve the water retention curves. In combination of Eq. (2) with the retention curve proposed by Fredlund and Xiang [31], a new retention curve between $S_{\mathrm{r}, \mathrm{w}}$ and $s$ under given temperature can finally be obtained as below [6]

$S_{\mathrm{r}, \mathrm{w}}=C(s)\left(\frac{1}{1+\left(\alpha_{\mathrm{T}} s\right)^{n}}\right)^{m_{\mathrm{r}}}, \quad \alpha_{\mathrm{T}}=\alpha\left(\frac{a_{1}+b_{1} T_{\mathrm{r}}}{a_{1}+b_{1} T}\right)^{b_{1}}$,

where $S_{\mathrm{r}, \mathrm{w}}$ the degree of saturation. $\alpha, m_{\mathrm{r}}$ and $n$ are the parameters relating to the air entry value of the soil, the residual water content and the slope of the suctionsaturation curve at the air entry value of the soil, respectively. $C(s)$ is the parameter relating to suction.

\subsubsection{Water permeability determination}

In soil mechanics, it is usual to use the permeability to describe the hydraulic characteristics. Generally, the permeability in saturated soils keeps constant under the room temperature. The permeability in unsaturated soils is usually determined by measuring the inflow flux and the outflow flux for a soil column sample in the oedometer test under the suction controlled condition with constant vertical stress or constant volumetric strain states. The effect of temperature on the relation between the permeability and the degree of saturation is significant particularly at the near saturated states. But if the degree of saturation is less than $70 \%$, no obvious temperature effect on the relation appears. It is also shown that the permeability increases with increasing void ratio in constant temperature and the degree of saturation.

The water permeability in unsaturated soils can be expressed as a function of void ratio $e$, water content $w$ and temperature $T$. It is usually assumed that the effects of $e, w, T$ on the water permeability $k_{\mathrm{w}}$ can be split and the expression for $k_{\mathrm{w}}$ is generally written in the form

$k_{\mathrm{w}}(e, w, T)=k_{\mathrm{w} 0}(e) k_{\mathrm{wr}}(w, T)=k_{\mathrm{w} 0}(e) k_{\mathrm{ws}}(w) k_{\mathrm{wT}}(T)$,

where $k_{\mathrm{w} 0}(e)$ is the intrinsic permeability depending on the pore structure and the void ratio, $k_{\mathrm{wr}}(w, T)$ the relative permeability, which is the function of the state variables $w$ and $T$ with omission of the effect of water pressure. Hueckel [32] indicated that the intrinsic permeability $k_{\mathrm{w} 0}$ in saturated clay with high density is related to the effective porosity $n_{2}$, defined as the porosity occupied by the bulk water, and can be expressed in the form

$k_{\mathrm{w} 0}=\frac{1}{\pi \tau^{2} S_{\mathrm{sm}}^{2}} \frac{\left(n_{2}\right)^{3}}{\left(1-n_{2}\right)^{2}}$,

where $S_{\mathrm{sm}}$ is the specific surface area relative to the mobile water space, $\pi$ a shape factor, $\tau$ tortuosity factor. A formula for $k_{\mathrm{w}}$ proposed by Romero and Gens [6] for unsaturated soils is given in the form

$k_{\mathrm{w}}(e, w, T)=k_{\mathrm{w} 0}\left(1+\mu_{\mathrm{T}}\left(T-T_{0}\right)\right) 10^{a e}\left(\frac{w-w_{\mathrm{ref}}}{\frac{e}{G s}-w_{\mathrm{ref}}}\right)^{\lambda}$,

where $w_{\text {ref }}$ is reference water content, $e / G s$ the saturated water content at the actual void ratio $e, \mu_{\mathrm{T}}$ an empirical coefficient fitting the relative viscosity.

\subsection{General aspects of the thermo-hydro-mechanical behaviours on oedometer tests}

Usually unsaturated soils can be classified into two types according to their behaviour in volumetric stability. They are stable structured soils characterised by low porosity and swelling tendency due to wetting and drained heating and meta-stable structured soils characterised by high porosity and collapse tendency due to wetting and drained heating. The constitutive behaviours observed in the experiments on the low-porosity and the high-porosity packings of unsaturated soils are separately discussed below. 
2.2.1. The results for suction controlled swelling/collapsel shrinkage behaviours on the low-porosity packing

The experiments are fulfilled under constant load in isothermal and non-isothermal paths. It is observed that the irreversible strains appear in main wetting and main drying paths. The plastic strains generated in the wetting and the drying paths are mainly caused by the suction decrease (SD) yield and the suction increase (SI) yield, respectively. SI yield locus is sensitive to temperature. The suction yield value decreases with increasing temperature. An expression for SI yield locus was proposed as [6]

SI $: s-\left\lfloor s_{0}+\langle S e\rangle^{k 1}\left(s_{\mathrm{I}}\left(\varepsilon_{\mathrm{v}}^{\mathrm{p}}, \Delta T\right)-s_{0}\right)\right\rfloor=0$,

where $\langle\mathrm{Se}\rangle$ designates the Macauly brackets applied to the effective bulk water saturation

$S e=\frac{S_{\mathrm{r}}-S_{\mathrm{res}}}{1-S_{\mathrm{res}}}$,

$k 1$ is an empirical constant and $\Delta T$ stands for the temperature difference with respect to a reference temperature $T_{\mathrm{r}}, s_{0}$ the maximum suction ever experienced past by the soil in $T_{\mathrm{r}}, s_{\mathrm{I}}$ the value of the current suction, $\varepsilon_{\mathrm{v}}^{\mathrm{p}}$ the plastic volumetric strain, $S_{\text {res }}$ the residual saturation.

Fig. 1 [6] shows remarkable effect of the suction on the $T-\varepsilon_{\mathrm{V}}$ curves in drained heating-cooling-reheating cycles under constant net vertical stress. A yield point is easily located on the $T-\varepsilon_{\mathrm{V}}$ curve with the higher suction

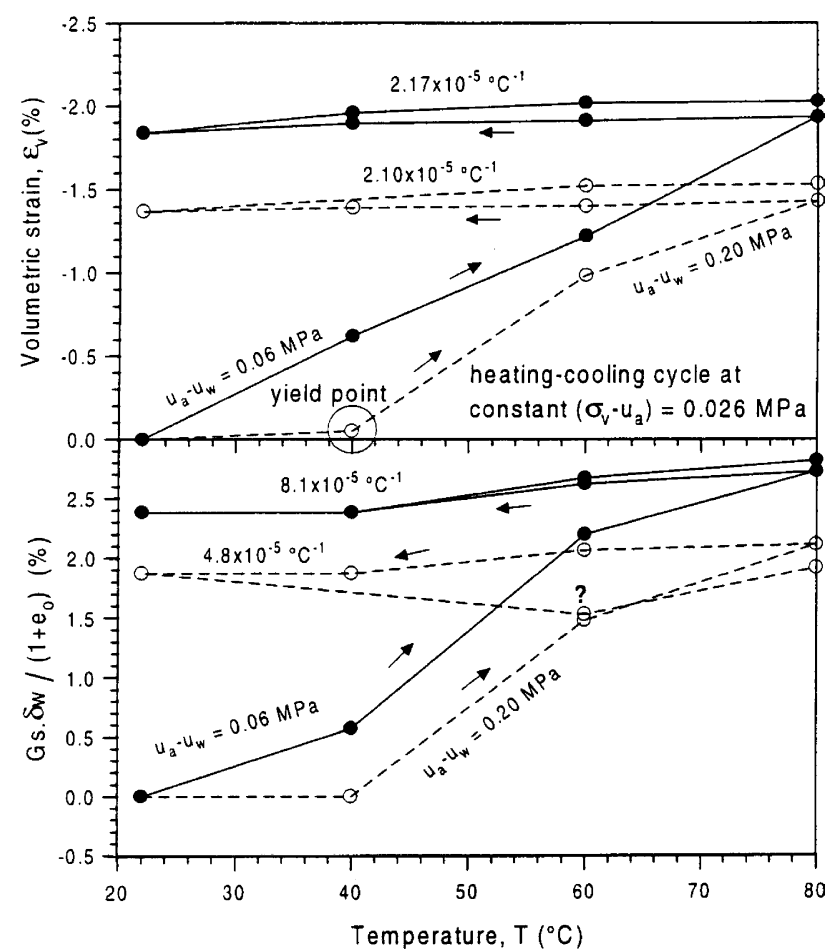

Fig. 1. Drained heating-cooling cycles under constant matrix suctions and constant net vertical stress $\left(\sigma_{\mathrm{v}}-u_{\mathrm{a}}=0.026 \mathrm{MPa}\right)$ (after [6] by Romero and Gens, 1999). value (i.e. $s=0.20 \mathrm{MPa}$ ) symbolised by the dashed broken line. The large irreversible strain emerges as the heating process along the line is developed to reach and beyond the critical point at which the temperature equals to $40{ }^{\circ} \mathrm{C}$. Gens [33] has pointed out that this behaviour is associated with SD yield locus. It is observed from the $T-\varepsilon_{\mathrm{V}}$ curve with the lower value of the suction (i.e. $s=0.06 \mathrm{MPa}$ ) symbolised by the solid line that the SD yield is already triggered at $22{ }^{\circ} \mathrm{C}$. The cooling and the re-heating paths are characterised as the elastic process.

\subsubsection{The results for suction controlled collapse(swell- ing)/shrinkage behaviours on the high-porosity packing}

The experiments are also carried out under constant load in isothermal and non-isothermal paths on high porosity packing. The irreversible plastic strains generated in the main wetting path and the following drying path can be clearly observed. The comparisons of volumetric strain-suction curves corresponding to different net vertical stresses in two isothermal conditions are illustrated in Fig. 2 [6]. It is observed that the suction variations at lower level of the net vertical stresses will cause swelling strains. On the contrary, shrinkage tendency is observed at higher level of the net vertical stresses.

\subsubsection{The volumetric strains on loading-unloading paths under controlled suction}

The volumetric strains generated on loading-unloading paths with constant suction behave in a similar tendency as that generated on the shrinkage-swelling paths with constant vertical stress. The pre-yield compressibility parameter $\kappa$ increases steadily until attaining a nearly constant value in the post-yield range. It also varies with suction as shown in Fig. 3 [6]. However, in most circumstances, the pre-yield compressibility parameter $\kappa$ is regarded as constant approximately. The post-yield compressibility parameter $\lambda(s, T)$ increases with increasing temperature.

\subsection{The results from isotropic swelling/collapse-shrink- age experiments}

Isotropic swelling/collapse-shrinkage experiments are performed in constant net mean stress in order to obtain such additional information as shear strain and the strain ratio between lateral strain and axial strain for modelling of thermo-hydro-mechanical behaviour. It is observed in normal consolidation states that the main heating will cause the irreversible plastic strain. On the other hand, the quasi-reversible expansion strain due to the main heating will emerge when the soil sample is in the over-consolidation state. Two processes take place during the drained heating stages. The first is the quasireversible process due to the expansion of the mineral- 


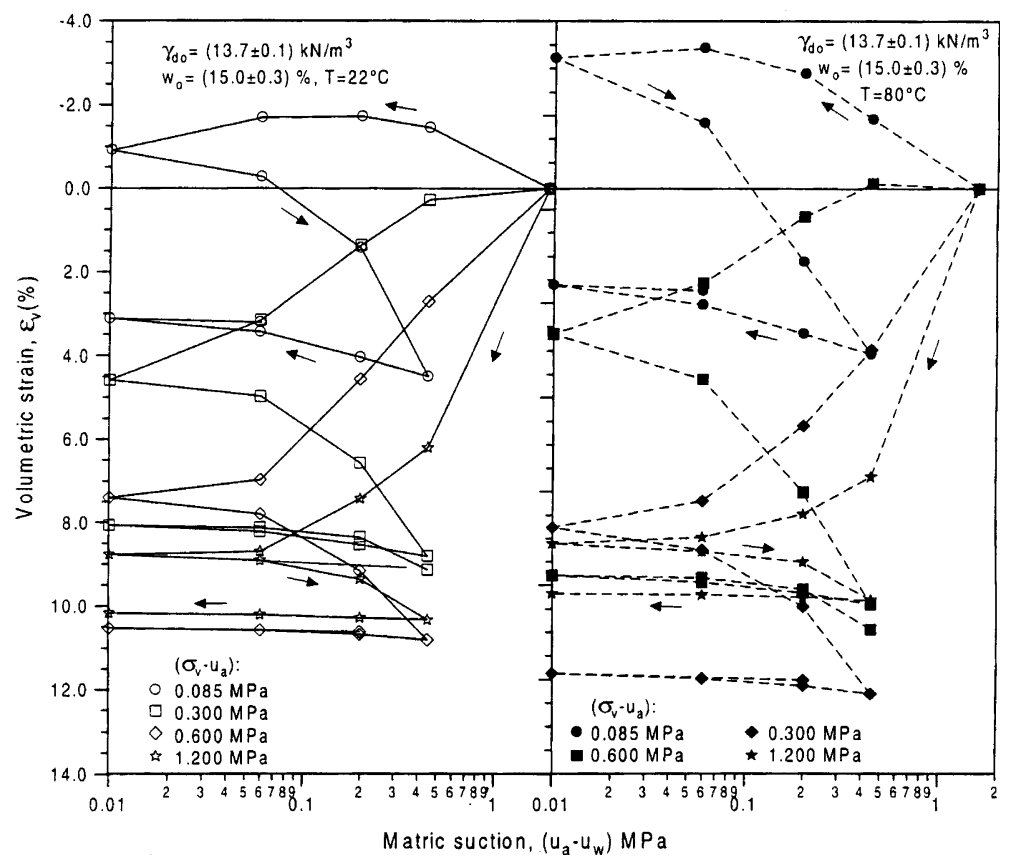

Fig. 2. Comparison of volumetric strains for the high-porosity packing in wetting-drying cycles at different net vertical stresses and temperatures (after [6] by Romero and Gens, 1999).

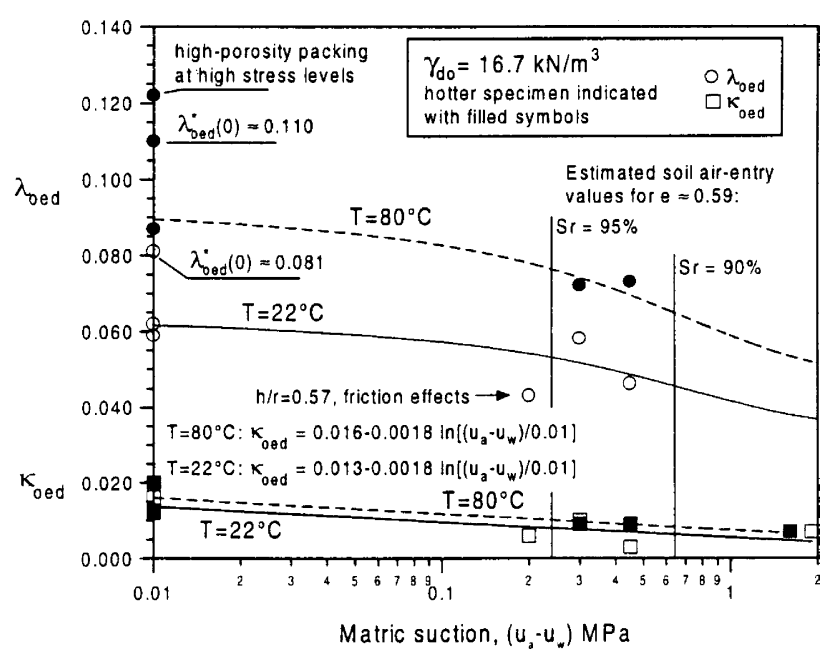

Fig. 3. $\lambda$ and $\kappa$ at different matrix suctions and temperatures (after [6] by Romero and Gens, 1999).

ogical components and adsorbed water related to intraaggregate water form. The reversible volumetric thermal strain presented [6] can be given in the form

$\left.\frac{\delta \varepsilon_{\mathrm{v}}^{\mathrm{e}}}{\delta T}\right|_{p^{\prime}}=\alpha_{\mathrm{m}}+\alpha_{0}\left(p^{\prime}\right)+\alpha_{1}\left(p^{\prime}\right) \Delta T$,

where $p^{\prime}$ is constant inter-granular stress, $\alpha_{\mathrm{m}}$ is solid mineral parameter which is assumed not to depend on stress level, $\alpha_{0}$ and $\alpha_{1}$ are the thermal expansion coefficients depending on stress states. The second is related to the irreversible meta-stable compressive phenomenon due to rearrangement of the structure of the soil skele- ton. The collapsing strains on the SD yield locus are associated with the reduction of elastic domain. The effect of temperature on the yield is reflected through the pre-consolidation stress $p_{0}\left(s, p_{0}^{*}\left(\varepsilon_{\mathrm{v}}^{\mathrm{p}}, \Delta T\right)\right)$ and cohesion $p_{\mathrm{s}}(s, \Delta T)$ in the expression $f\left(p, q, s, p_{0}\left(p_{0}^{*}\right), p_{\mathrm{s}}\right)=0$ for the yield locus.

\section{The hydro-thermo-mechanical model for unsaturated soils}

As discussed above, we can clearly notice that the hydro-mechanical behaviour in unsaturated soils strongly depends on temperature variation. Therefore, it is necessary to extend the hydro-mechanical constitutive models for unsaturated soils to the thermo-hydromechanical ones. In this paper, a new thermo-hydromechanical constitutive model for unsaturated soils is presented based on the existing, widespread used model - CAP model.

The general framework of the CAP model $[34,35]$ for unsaturated soils is composed of the following four yield loci:

(1) The state boundary surface (SBS) proposed by Alonso et al. [27]

$f_{1}=I I_{\hat{\sigma}}^{2}+m^{2}\left(I_{\sigma}-3 p_{\mathrm{s}}(s)\right)\left(I_{\sigma}+3 p_{0}(s)\right)=0$.

(2) The critical state line (CSL) presented by Drucker and Prager [36]

$f_{2}=I I_{\hat{\sigma}}+m\left(I_{\sigma}-3 p_{\mathrm{s}}(s)\right)=0$. 
(3) The traction model (TM) [33]

$f_{3}=I_{\sigma}-3 \sigma_{\mathrm{t}}=0$.

(4) Suction increase (SI) curve also proposed by Alonso et al. [27]

$f_{4}=s-s_{0}=0$,

where $I_{\sigma}$ and $I I_{\hat{\sigma}}$ are the first stress tensor invariant and the second deviatoric stress tensor invariant, respectively, $p_{\mathrm{s}}(s)$ the cohesion, $p_{0}(s)$ the preconsolidation pressure and $m$ the parameter defined by the following expression:

$m=\frac{2 \sin \phi_{\mathrm{c}}}{\sqrt{3}\left(3-\sin \phi_{\mathrm{c}}\right)}$,

$\phi_{\mathrm{c}}$ is the frictional angle for stress paths in compression. The pre-consolidation pressure $p_{0}(s)$ varies with the suction according to the loading collapse (LC) curve as follows:

$$
\begin{aligned}
p_{0}(s)= & p_{\mathrm{c}}\left(\frac{p_{0}^{*}}{p_{\mathrm{c}}}\right)^{\frac{\lambda(0)-\kappa}{\lambda(s)-\kappa}} \quad \text { in which } \lambda(s)=\lambda(0)((1-\gamma) \\
& \times \exp (-\beta s)+\gamma),
\end{aligned}
$$

where $p_{0}^{*}$ is the pre-consolidation pressure in saturated state, $p_{\mathrm{c}}$ the reference pressure, $\beta, \gamma$ are the parameter determined by corresponding experiments. The cohesion $p_{\mathrm{s}}$ also depends on the suction in the form

$p_{\mathrm{s}}(s)=p_{\mathrm{s}}(0)+k \cdot s$,

where $p_{\mathrm{s}}(0)$ is the initial cohesion, $k$ is the coefficient, $\sigma_{\mathrm{t}}$ is the given traction stress. The associated plasticity is considered for this yield surface and no hardening rule is included. The CAP model is illustrated in the $\left(I_{\sigma}, I I_{\hat{\sigma}}, s\right)$ space shown in Fig. 4. Below the effects of temperature on hydro-mechanical parameters in the CAP model are discussed in detail.

\subsection{The thermal softening curve and the loading-collapse curve}

The preconsolidation pressure $p_{0}^{*}$ in saturated state varies with temperature following the thermal soften-

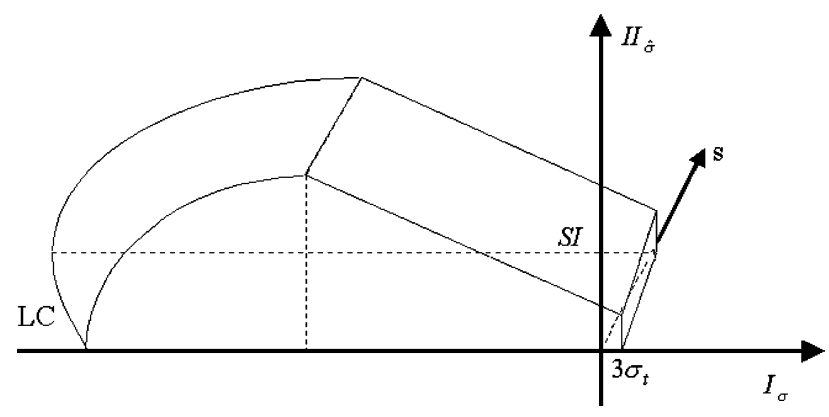

Fig. 4. The CAP model in the $\left(I_{\sigma}, I I_{\hat{\sigma}}, s\right)$ space. ning curve (TS) proposed by Hueckel and Borsetto [1] in the form

$p_{0}^{*}\left(\varepsilon_{\mathrm{v}}^{\mathrm{p}}, \Delta T\right)=p_{0}^{*}\left(\varepsilon_{\mathrm{v}}^{\mathrm{p}}\right)+A(\Delta T)$,

where

$A(\Delta T)=a_{1} \Delta T+a_{2} \Delta T|\Delta T|$,

$a_{1}, a_{2}$ are the coefficients depending on thermal sensibility of the soil. It is assumed that the thermal softening is uncoupled with strain hardening and is illustrated in terms of the TS curve in $p_{0}^{*}-T$ plane shown in Fig. 5 [22].

The relationship of preconsolidation pressure $p_{0}(s, T)$ with the suction $s$ and temperature $T$ in unsaturated soils is still described in format of loading-collapse (LC) curve defined as

$p_{0}(s, T)=p_{\mathrm{c}}\left(\frac{p_{0}^{*}\left(\varepsilon_{\mathrm{v}}^{\mathrm{p}}, T\right)}{p_{\mathrm{c}}}\right)^{[\lambda(0)-\kappa] /[\lambda(s)-\kappa]}$.

However, experimental results indicate that the plastic slope $\lambda(s)$ varies with the heating-cooling cycles, namely, $\lambda=\lambda(s, T)$. A simplified expression for $\lambda=$ $\lambda(s, T)$ used in the present work is given in an uncoupled form as below

$$
\begin{aligned}
\lambda(s, \Delta T)= & \lambda\left(s, T_{\mathrm{r}}\right)+\beta_{1} \Delta T+\beta_{2} \Delta T|\Delta T| \\
= & \lambda\left(0, T_{\mathrm{r}}\right)[(1-\gamma) \exp (-\beta s)+\gamma]+\beta_{1} \Delta T \\
& +\beta_{2} \Delta T|\Delta T|,
\end{aligned}
$$

where $\beta_{1}, \beta_{2}$ are the empirical coefficients. Fig. 6 illustrates the LC curves corresponding two different temperatures.

The cohesion also varies with temperature and can be expressed in the form

$p_{\mathrm{s}}(s, \Delta T)=p_{\mathrm{s}}\left(0, T_{\mathrm{r}}\right)+k(s, \Delta T) s$.

However, it is found according to the experimental observations that the variation of the cohesion with increasing temperature is much smaller in value than that relating with increasing suction. For the sake of convenience in the derivation of the relative formulations, it is assumed that the cohesion is only related to the suction.

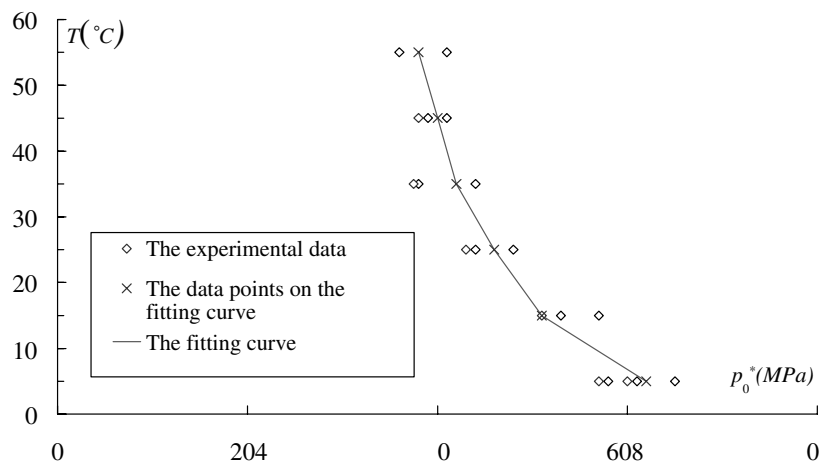

Fig. 5. Thermal soften function in $p_{0}^{*}-T$ plane (after [22] by Eriksson, 1989). 


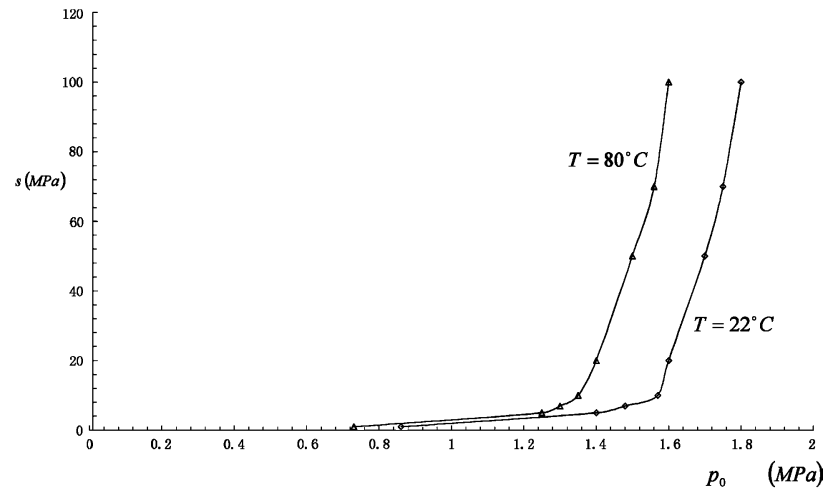

Fig. 6. Loading-collapse curves in $p_{0}-s$ plane in two different temperatures.

Temperature is supposed to have no influence on the traction stress. SI curve also varies with increasing temperature as a lower air-entry value under surfacetension reasoning is expected at higher temperatures. SI curve can then be chosen [6] as that shown in Eq. (7).

\subsection{The thermal yield curve}

In the following the irreversible deformation due to the effect of temperature variation is discussed. The experimental results indicate that increasing temperature beyond a certain prescribed value $T_{0}$ will cause plastic strains even in over-consolidation states. This plastic yielding phenomenon is simply described by the socalled thermal yield curve (TYC). It should be pointed out that it is rather cursory to use a straight line $\left(T=T_{0}\right)$ for simulating the thermal yield. A more sophisticated form of the thermal yield curve needs to be built on the basis of the related experimental results. Cui et al. [5] proposed a form for TYC for saturated soils, as shown in Fig. 7, given by

$T=\left(T_{\mathrm{r}}-T_{0}\right) \exp \left(-\beta_{3} p_{0}\right)+T_{0}$,

where $\beta_{3}$ is the parameter defining the curvature of the curves. However, the above form of TYC is not included the effects of suction. Further research work is required to improve the thermal yield curve.

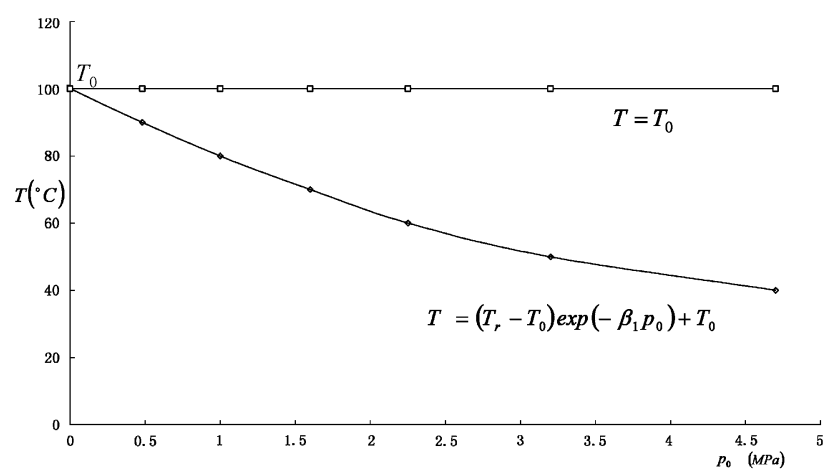

Fig. 7. Thermal yield curve in $p_{0}-T$ plane.

\subsection{The yield surfaces}

To take into account the effects of temperature, the multiplicate yield surfaces of the CAP model expressed by Eqs. (10)-(13) and (22) are extended and given in the following yield formulae:

$$
\begin{aligned}
& f_{1}=I I_{\hat{\sigma}}^{2}+m^{2}\left(I_{\sigma}-3 p_{\mathrm{s}}(s)\right)\left(I_{\sigma}+3 p_{0}(s, \Delta T)\right)=0, \\
& f_{2}=I I_{\hat{\sigma}}+m\left(I_{\sigma}-3 p_{\mathrm{s}}(s)\right)=0, \\
& f_{3}=I_{\sigma}-3 \sigma_{\mathrm{t}}=0, \\
& f_{4}=s-\left\lfloor s_{0}+\langle S e\rangle^{k 1}\left(s_{\mathrm{I}}\left(\varepsilon_{\mathrm{v}}^{\mathrm{p}}, \Delta T\right)-s_{0}\right)\right\rfloor=0, \\
& f_{5}=T-T_{0}=0 \text { or } f_{5}=T-\left(T_{\mathrm{r}}-T_{0}\right) \exp \left(-\beta_{3} p_{0}\right)-T_{0} .
\end{aligned}
$$

As the four independent variables $\left(I_{\sigma}, I I_{\hat{\sigma}}, s, T\right)$ are included in the model, it is impossible to illustrate it in only one figure. We give three plots in the following three different 3D spaces as shown in Fig. 8.
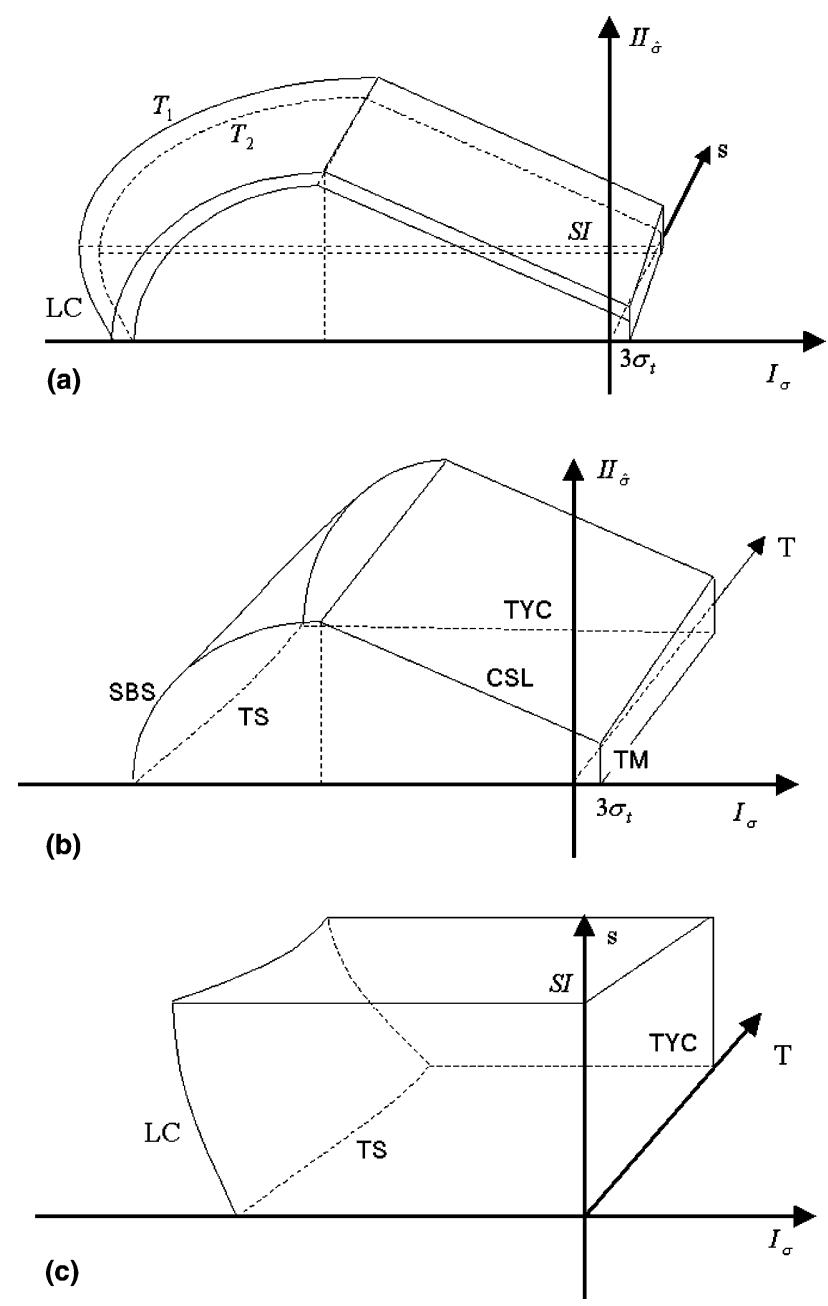

Fig. 8. The constitutive model in (a) the $\left(I_{\sigma}, I I_{\hat{\sigma}}, s\right)$ space with different temperature $T_{2}>T_{1}$; (b) the $\left(I_{\sigma}, I_{\hat{\sigma}}, T\right)$ space; (c) the $\left(I_{\sigma}, s, T\right)$ space. 


\subsection{The constitutive relations in rate form}

Let us express the present constitutive model in the rate form. The total strain rate is additatively decomposed of three parts owing to the mechanical, thermal and suction effects, respectively, and each part of them can be further additatively decomposed into elastic and plastic portions, i.e.

$$
\begin{aligned}
\dot{\varepsilon}_{i j} & =\dot{\varepsilon}_{i j}^{\mathrm{m}}+\dot{\varepsilon}_{i j}^{\mathrm{s}}+\dot{\varepsilon}_{i j}^{\mathrm{T}} \\
& =\dot{\varepsilon}_{i j}^{\mathrm{m}, \mathrm{e}}+\dot{\varepsilon}_{i j}^{\mathrm{m}, \mathrm{p}}+\dot{\varepsilon}_{i j}^{\mathrm{s}, \mathrm{e}}+\dot{\varepsilon}_{i j}^{\mathrm{s}, \mathrm{p}}+\dot{\varepsilon}_{i j}^{\mathrm{T}, \mathrm{e}}+\dot{\varepsilon}_{i j}^{\mathrm{T}, \mathrm{p}} .
\end{aligned}
$$

The total stress rate can be expressed by the Hook's law in terms of the elastic portion of the mechanical strain rate as follows:

$\dot{\sigma}_{i j}=C_{i j k l}^{\mathrm{e}} \dot{\varepsilon}_{k l}^{\mathrm{m}, \mathrm{e}}$

where $C_{i j k l}^{\mathrm{e}}$ is the elastic compliance tensor. The elastic strain $\dot{\varepsilon}_{i j}^{\text {s,e }}$ due to the suction variation is given by

$\dot{\varepsilon}_{i j}^{\mathrm{s}, \mathrm{e}}=\frac{\kappa_{\mathrm{s}}}{(1+e)} \frac{\dot{s}}{\left(s+p_{\mathrm{a}}\right)} \delta_{i j}=h_{i j}^{\mathrm{e}} \dot{s}$,

where $\kappa_{\mathrm{s}}$ is elastic stiffness parameter for changes in suction. From the experimental results, the elastic strain $\dot{\varepsilon}_{i j}^{\text {Te e }}$ due to the temperature change is evaluated through a thermal expansion parameter $\alpha_{2}$

$\dot{\varepsilon}_{i j}^{\mathrm{T}, \mathrm{e}}=\alpha_{2} \dot{T} \delta_{i j}=T_{i j}^{\mathrm{e}} \cdot \dot{T}$.

The plastic strain rate $\dot{\varepsilon}_{i j}^{\mathrm{m}, \mathrm{p}}$ due to mechanical effect is given according to the plastic flow rule

$\dot{\varepsilon}_{i j}^{\mathrm{m}, \mathrm{p}}=\dot{\lambda}^{\mathrm{p}} \frac{\partial g}{\partial \sigma_{i j}}$

in which $g$ is the plastic potential function and the nonassociated plasticity is considered. one can obtain its associated form by simply assuming $g=f, f$ is the associated yield function.

The plastic strain part corresponding to the suction variation is written as

$\dot{\varepsilon}_{i j}^{\mathrm{s}, \mathrm{p}}=\frac{\lambda_{\mathrm{s}}-\kappa_{\mathrm{s}}}{(1+e)} \frac{\dot{s}}{\left(s+p_{a}\right)} \delta_{i j}=h_{i j}^{\mathrm{p}} \dot{s}$,

where $\lambda_{\mathrm{s}}$ is plastic stiffness parameter for changes in suction.

The plastic strain part due to thermal effect can be determined according to the following consistent yield condition:

$\frac{\partial f}{\partial T} \delta T+\frac{\partial f}{\partial \varepsilon_{i j}^{\mathrm{T}, \mathrm{p}}} \delta \varepsilon_{i j}^{\mathrm{T}, \mathrm{p}}=0$

from which it is given that $\dot{\varepsilon}_{i j}^{\mathrm{T}, \mathrm{p}}=T_{i j}^{\mathrm{p}} \dot{T}$.

As CSL is activated by temperature variation, $T_{i j}^{\mathrm{p}}$ can be calculated as below

$$
\begin{aligned}
T_{i j}^{\mathrm{p}} & =\frac{\delta \varepsilon_{i j}^{\mathrm{T}, \mathrm{p}}}{\delta T}=\frac{-\frac{\partial f}{\partial p_{0}} \frac{\partial p_{0}}{\partial p_{0}^{*}} \frac{\partial p_{0}^{*}}{\partial T}}{\frac{\partial f}{\partial p_{0}} \frac{\partial p_{0}}{\partial p_{0}^{*}} \frac{\partial p_{0}^{*}}{\partial \varepsilon_{i j}^{T, p}}}=-\frac{\frac{\partial p_{0}^{*}}{\partial T}}{\frac{\partial p_{0}^{*}}{\partial \varepsilon_{i j}^{T, p}}} \\
& =-\frac{(\lambda(0)-\kappa)\left(a_{1}+2 a_{2} \Delta T\right)}{(1+e) p_{0}^{*}} .
\end{aligned}
$$

While TYC is activated, the volumetric plastic strain can be computed according to the expression proposed by Cui and Delage as

$\dot{\varepsilon}_{i j}^{\mathrm{T}, \mathrm{p}}=\exp \left(\alpha_{\mathrm{p}} \dot{T}\right)-a \alpha_{\mathrm{p}} \dot{T}-1$,

where $a$ is the parameter equal to one approximately, $\alpha_{\mathrm{p}}$ can be determined by corresponding experiments.

Substitution of Eqs. (25)-(29) and (31) into Eq. (24) gives

$\dot{\varepsilon}_{i j}=C_{i j k l}^{\mathrm{e}^{-1}} \dot{\sigma}_{k l}+\dot{\lambda}^{\mathrm{p}} \frac{\partial g}{\partial \sigma_{i j}}+h_{i j}^{\mathrm{e}} \dot{s}+h_{i j}^{\mathrm{p}} \dot{s}+T_{i j}^{\mathrm{e}} \dot{T}+T_{i j}^{\mathrm{p}} \dot{T}$.

For a yield function $f$ with the hardening/softening rule depending on the internal state variable $\theta$, the plastic consistency condition of the yield function can be written as

$\dot{f}=\frac{\partial f}{\partial \sigma} \dot{\sigma}+\frac{\partial f}{\partial \theta} \dot{\theta}+\frac{\partial f}{\partial s} \dot{s}+\frac{\partial f}{\partial T} \dot{T}=0$,

where

$\dot{\sigma}_{i j}=C_{i j k l}^{\mathrm{e}}\left[\dot{\varepsilon}_{k l}-\dot{\varepsilon}_{k l}^{\mathrm{m}, \mathrm{p}}-\dot{\varepsilon}_{k l}^{\mathrm{s}, \mathrm{e}}-\dot{\varepsilon}_{k l}^{\mathrm{s}, \mathrm{p}}-\dot{\varepsilon}_{k l}^{\mathrm{T}, \mathrm{e}}-\dot{\varepsilon}_{k l}^{\mathrm{T}, \mathrm{p}}\right\rfloor$,

$\dot{\theta}=\frac{\mathrm{d} \theta}{\mathrm{d} \varepsilon^{\mathrm{p}}}\left(v a l_{\lambda} \cdot \dot{\lambda}_{\mathrm{p}}+v a l_{\mathrm{s}} \cdot \dot{s}+v a l_{\mathrm{T}} \cdot \dot{T}\right)$,

$v a l_{\lambda}, v l_{\mathrm{s}}$ and $v a l_{\mathrm{T}}$ stand for the tensors $\partial g / \partial \sigma_{i j}, h_{i j}^{\mathrm{p}}$ and $T_{i j}^{\mathrm{p}}$, respectively. The plastic volumetric strain $\varepsilon_{\mathrm{v}}^{\mathrm{p}}$ is taken as the internal state variable $\theta$ to govern the evolution of the multiplicate yield surfaces. Substitution of expressions (36) and (37) into Eq. (35) gives

$$
\begin{aligned}
\dot{f}= & \frac{\partial f}{\partial \sigma_{i j}} C_{i j k l}^{\mathrm{e}}\left[\dot{\varepsilon}_{k l}-\dot{\lambda}^{\mathrm{p}} \frac{\partial g}{\partial \sigma_{i j}}-h_{k l}^{\mathrm{e}} \dot{s}-h_{k l}^{\mathrm{p}} \dot{s}-T_{k l}^{\mathrm{e}} \dot{T}-T_{k l}^{\mathrm{p}} \dot{T}\right] \\
& +\frac{\partial f}{\partial \theta} \frac{\partial \theta}{\partial \varepsilon^{\mathrm{p}}}\left[v a l_{\lambda} \cdot \dot{\lambda}^{\mathrm{p}}+v a l_{\mathrm{s}} \cdot \dot{s}+v a l_{\mathrm{T}} \cdot \dot{T}\right] \\
& +\frac{\partial f}{\partial s} \dot{s}+\frac{\partial f}{\partial T} \dot{T}=0
\end{aligned}
$$

and results in

$$
\dot{\lambda}^{\mathrm{p}}=\frac{\frac{\partial f}{\partial \sigma_{i j}} C_{i j k l}^{\mathrm{e}} \dot{\varepsilon}_{k l}-\frac{\partial f}{\partial \sigma_{i j}} C_{i j k l}^{\mathrm{e}}\left[h_{k l}^{\mathrm{e}}+h_{k l}^{\mathrm{p}}\right] \dot{s}-\frac{\partial f}{\partial \sigma_{i j}} C_{i j k l}^{\mathrm{e}}\left[T_{k l}^{\mathrm{e}}+T_{k l}^{\mathrm{p}}\right] \dot{T}+\frac{\partial f}{\partial \theta} \frac{\partial \theta}{\partial \varepsilon^{\mathrm{p}}}\left[v a l_{\mathrm{s}} \cdot \dot{s}+v a l_{\mathrm{T}} \dot{T}\right]+\frac{\partial f}{\partial s} \dot{s}+\frac{\partial f}{\partial T} \dot{T}}{\frac{\partial f}{\partial \sigma_{i j}} C_{i j k l}^{\mathrm{e}} \frac{\partial g}{\partial \sigma_{k l}}-v a l_{\lambda} \frac{\partial f}{\partial \theta} \frac{\partial \theta}{\partial \varepsilon^{\mathrm{p}}}} .
$$


Finally, the stress rate in the consistent form can then be computed as follows:

$$
\begin{aligned}
\dot{\sigma}_{i j}= & {\left[C_{i j k l}^{\mathrm{e}}-\frac{\frac{\partial f}{\partial \sigma_{a b}} C_{a b k l}^{\mathrm{e}} C_{i j c d}^{\mathrm{e}} \frac{\partial g}{\partial \sigma_{c d}}}{\frac{\partial f}{\partial \sigma_{m n}} C_{m n o p}^{\mathrm{e}} \frac{\partial g}{\partial \sigma_{o p}}-v a l_{\lambda} \frac{\partial f}{\partial \theta} \frac{\partial \theta}{\partial \varepsilon^{\mathrm{p}}}}\right] \dot{\varepsilon}_{k l} } \\
& -\left[C_{i j k l}^{\mathrm{e}}\left(h_{k l}^{\mathrm{e}}+h_{k l}^{\mathrm{p}}\right)+\frac{C_{i j k l}^{\mathrm{e}} \frac{\partial g}{\partial \sigma_{k l}}}{\frac{\partial f}{\partial \sigma_{m n}} C_{m n o p}^{\mathrm{e}} \frac{\partial g}{\partial \sigma_{o p}}-v a l_{\lambda} \frac{\partial f}{\partial \theta} \frac{\partial \theta}{\partial \varepsilon^{\mathrm{p}}}}\right. \\
& \left.\times\left(\frac{\partial f}{\partial s}+v a l_{\mathrm{s}} \frac{\partial f}{\partial \theta} \frac{\partial \theta}{\partial \varepsilon^{\mathrm{p}}}-\frac{\partial f}{\partial \sigma_{m n}} C_{m n k l}^{\mathrm{e}}\left(h_{k l}^{\mathrm{e}}+h_{k l}^{\mathrm{p}}\right)\right)\right] \dot{s} \\
& -\left[C_{i j k l}^{\mathrm{e}}\left(T_{k l}^{\mathrm{e}}+T_{k l}^{\mathrm{p}}\right)+\frac{C_{i j k l} \frac{\partial g}{\partial \sigma_{k l}}}{\frac{\partial f}{\partial \sigma_{m n}} C_{m n o p}^{\mathrm{e}} \frac{\partial g}{\partial \sigma_{o p}}-v a l_{\lambda} \frac{\partial f}{\partial \theta} \frac{\partial \theta}{\partial \varepsilon^{\mathrm{p}}}}\right. \\
& \left.\times\left(\frac{\partial f}{\partial T}+v a l_{\mathrm{T}} \frac{\partial f}{\partial \theta} \frac{\partial \theta}{\partial \varepsilon^{\mathrm{p}}}-\frac{\partial f}{\partial \sigma_{m n}} C_{m n k l}^{\mathrm{e}}\left(T_{k l}^{\mathrm{e}}+T_{k l}^{\mathrm{p}}\right)\right)\right] \dot{T} .
\end{aligned}
$$

It is remarked that in contrast with single yield surface plasticity, a particular attention to determine the plastic strain increments has to be given to the corner where two yield surfaces are active. A backward Euler return mapping procedure with determination of the active yield conditions on the basis of the Kuhn-Tuker conditions for non-smooth multi-surface plasticity is required $[35,37]$.

\section{Numerical examples}

As the first example, a soil cube in drained condition subjected to a step heating uniformly applied over the whole region of the cube is considered. The uniformly distributed pressure loading shown in Fig. 9 is applied on the three edges of the cube. The purpose of the simulation is to verify the present constitutive

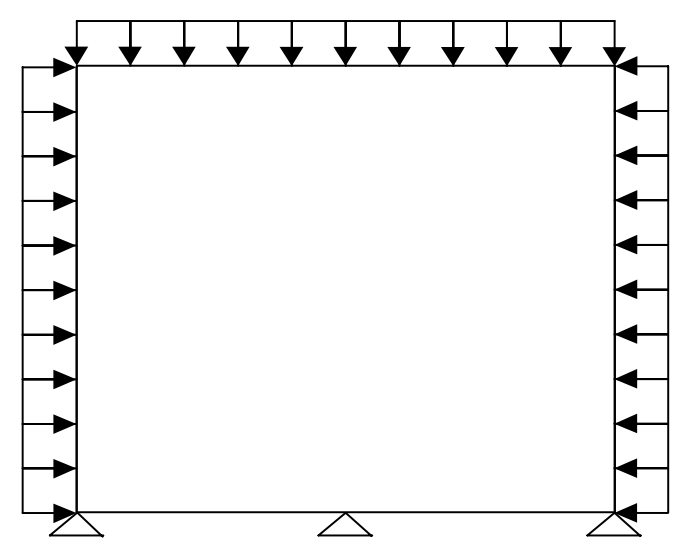

Fig. 9. The soil cube for isotropic drained test. model via a comparison of the results [6] obtained by the modelling with corresponding experimental ones. The finite element mesh with only one eight-node element is used. The material property data used for the element are shown in Table 1. Two cases with two different initial consolidation pressures applied on the soil cube are performed. The first case is performed in the over-consolidation state, in which $\sigma_{\mathrm{m}}-p_{\mathrm{a}}=0.10$ $\mathrm{MPa}$ and $s=p_{\mathrm{a}}-p_{\mathrm{w}}=0.20 \mathrm{MPa}$ are specified, temperature increases from 295 to $355 \mathrm{~K}$. The second is performed in the normal consolidation state, in which $\sigma_{\mathrm{m}}-p_{\mathrm{a}}=1.0 \mathrm{MPa}$ and $s=p_{\mathrm{a}}-p_{\mathrm{w}}=0.20 \mathrm{MPa}$ are

Table 1

Parameters relating to thermo-hydro-mechanical behaviour

\begin{tabular}{llll}
\hline$\lambda(0)$ & 0.057 & $a$ & 1.0 \\
$\kappa$ & 0.005 & $b$ & -0.037 \\
$\beta$ & $1.336 \mathrm{MPa}^{-1}$ & $k$ & 1 \\
$\gamma$ & 0.015 & $\lambda_{\mathrm{s}}$ & 0.25 \\
$p_{0}^{*}\left(T_{\mathrm{r}}\right)$ & $1.0 \mathrm{MPa}$ & $\kappa_{\mathrm{s}}$ & 0.11 \\
$p_{\mathrm{c}}$ & $0.585 \mathrm{MPa}$ & $a_{1}$ & $-1500 \mathrm{~Pa} / \mathrm{K}$ \\
$\phi_{\mathrm{c}}$ & $35^{\circ}$ & $a_{2}$ & $63 \mathrm{~Pa} / \mathrm{K}$ \\
$T_{0}$ & $373 \mathrm{~K}$ & $\alpha_{2}$ & $0.000050\left(\mathrm{~K}^{-1}\right)$ \\
$T_{\mathrm{r}}$ & $295 \mathrm{~K}$ & $v$ & 0.4 \\
$e_{0}$ & 0.679 & $\rho_{\mathrm{w}}$ & $1000 \mathrm{~kg} / \mathrm{m}^{3}$ \\
$s_{0}$ & $18 \mathrm{MPa}$ & $\rho_{\mathrm{s}}$ & $2750 \mathrm{~kg} / \mathrm{m}^{3}$ \\
\hline
\end{tabular}
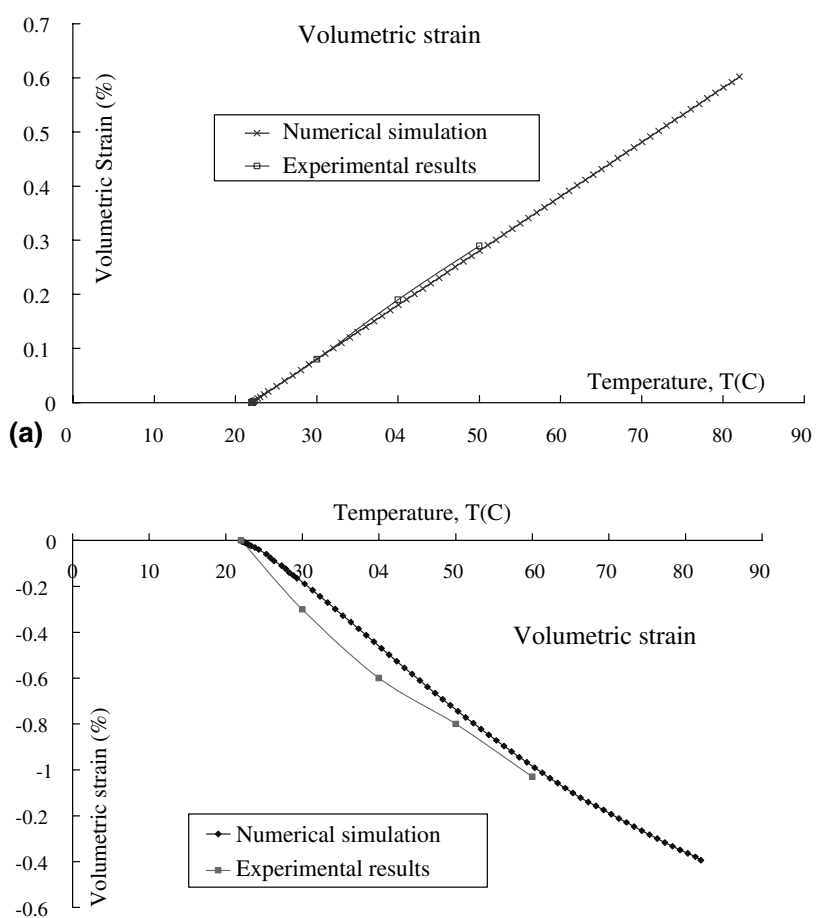

(b)

Fig. 10. Drained volumetric strains versus temperatures for numerical simulation and experimental results in (a) overconsolidation state (b) normal consolidation state. 
specified with the same heating process as applied to the first case. Fig. 10 illustrates the variations of the volumetric stain versus increasing temperature in both cases. The experimental results are also illustrated in the same figure.

It is observed from the results for this example that effect of the thermal softening on the yield surfaces caused by heating process is compensated by that of strain hardening so that the mechanical balance still remains. As a consequence, additional irreversible volumetric strains characterised as the thermal plasticity phenomenon occur and develop.

The second example considers a soil column, which is $5 \mathrm{~m}$ deep and $1 \mathrm{~m}$ wide. Fourteen non-uniformly divided eight-node element mesh shown in Fig. 11 is used for numerical modelling of the example. The initial temperatures 353 and $293 \mathrm{~K}$ are prescribed for the eight nodes of the first element and all of the rest nodes in the mesh, respectively. As the boundary condition, the temperature equal to $353 \mathrm{~K}$ for the three nodes located at the top of the column is fixed in the heat conduction process. The initial stress equal to $1.2 \mathrm{MPa}$ is applied on the whole column, which is as same as the preconsolidation pressure prescribed to the column. The material parameters used in the example are listed in Table 2. The four cases corre-

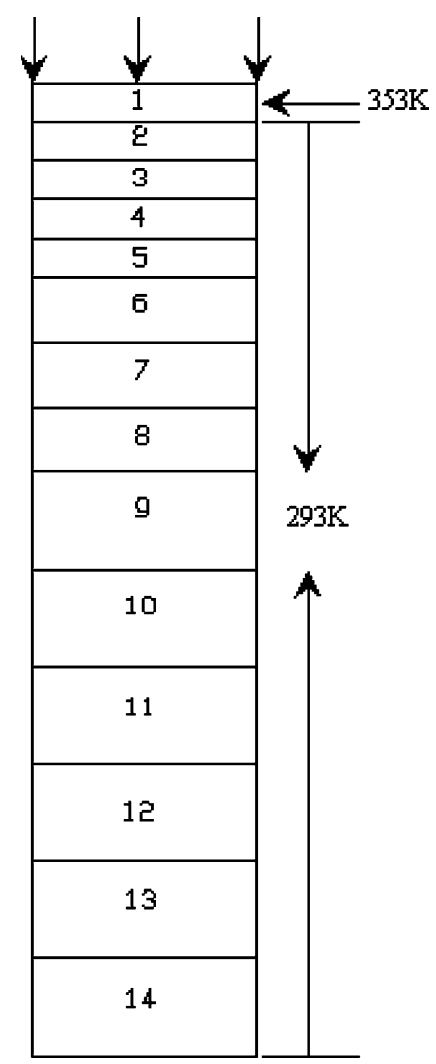

Fig. 11. Geometry and finite element mesh of the soil column.
Table 2

Parameters related to thermo-hydro-mechanical behaviour

\begin{tabular}{llll}
\hline$\lambda(0)$ & 0.4041 & $a$ & 1.0 \\
$\kappa$ & 0.014 & $b$ & -0.037 \\
$\beta$ & $0.41 \mathrm{MPa}^{-1}$ & $k$ & 1 \\
$\gamma$ & 0.30 & $\lambda_{\mathrm{s}}$ & 0.25 \\
$p_{0}^{*}\left(T_{\mathrm{r}}\right)$ & $1.6 \mathrm{MPa}$ & $\kappa_{\mathrm{s}}$ & 0.11 \\
$p_{\mathrm{c}}$ & $1.20 \mathrm{MPa}$ & $a_{1}$ & $-1500 \mathrm{~Pa} / \mathrm{K}$ \\
$\phi_{\mathrm{c}}$ & $35^{\circ}$ & $a_{2}$ & $63 \mathrm{~Pa} / \mathrm{K}$ \\
$T_{0}$ & $373 \mathrm{~K}$ & $\alpha_{2}$ & $0.000050\left(\mathrm{~K}^{-1}\right)$ \\
$T_{\mathrm{r}}$ & $295 \mathrm{~K}$ & $v$ & 0.4 \\
$e_{0}$ & 0.667 & $\rho_{\mathrm{w}}$ & $1000 \mathrm{~kg} / \mathrm{m}^{3}$ \\
$s_{0}$ & $18 \mathrm{MPa}$ & $\rho_{\mathrm{s}}$ & $2750 \mathrm{~kg} / \mathrm{m}^{3}$ \\
\hline
\end{tabular}

sponding to different loading and critical temperature conditions are considered. The first and the second cases are carried out under the increasing vertical load path ranging from 1.2 to $2.0 \mathrm{MPa}$ applied on the top of the soil column as shown in Fig. 11. The critical temperatures defined as material parameters for the two cases are different. For the first case the critical temperature is equal $363 \mathrm{~K}$, hence, the heat conduction process along the column in the first case will not trigger TYC causing plastic strains. Whereas the critical temperature specified as the material parameter for the second case is $343 \mathrm{~K}$. Therefore, the front of the zone of the column, at which the temperature exceeds the prescribed critical value and the plastic strains are induced with the heat conduction process, will be gradually advanced from the top toward the bottom of the column. The third and the forth cases concern with the constant vertical load of $1.2 \mathrm{MPa}$ applied on the top of the column. The critical temperatures specified as the material parameters for the third and the forth cases are assumed as the same as those specified in the first and the second cases, respectively. The results for the vertical strain distributions along the column for the four cases at a series of time steps are illustrated in Fig. 12.

Through the comparisons of the four resulting volumetric strain distributions it can be seen how the thermal yield surface influences to the resulting volumetric strains. It indicates that TYC will play an important role in the present constitutive model.

The heating example on a sample of unsaturated Boom clay proposed as the Benchmark Test 2.2 is, as the third example, simulated. The sample was compacted into a cylindrical stainless steel cell with the inner diameter $15 \mathrm{~cm}$, the inner height $15.6 \mathrm{~cm}$ and the thickness $3.6 \mathrm{~cm}$. The heater with length of $10 \mathrm{~cm}$ and the diameter $2 \mathrm{~cm}$ is inserted into the centre of the cell as shown in Fig. 13. The domain taken for the modelling of this example is composed of the soil sample, the porous plate and the steel case but no heater. The finite element mesh with 629 nodes and 

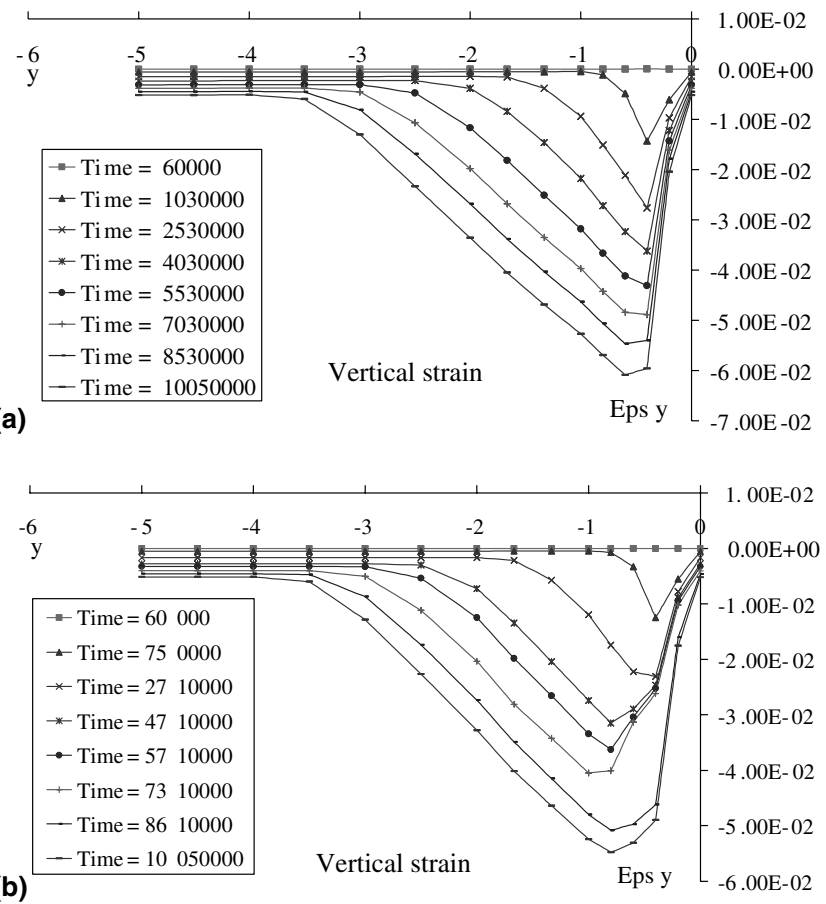

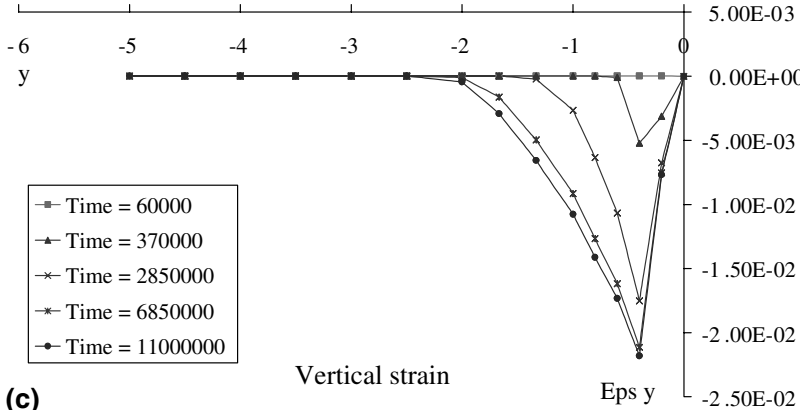

(c)

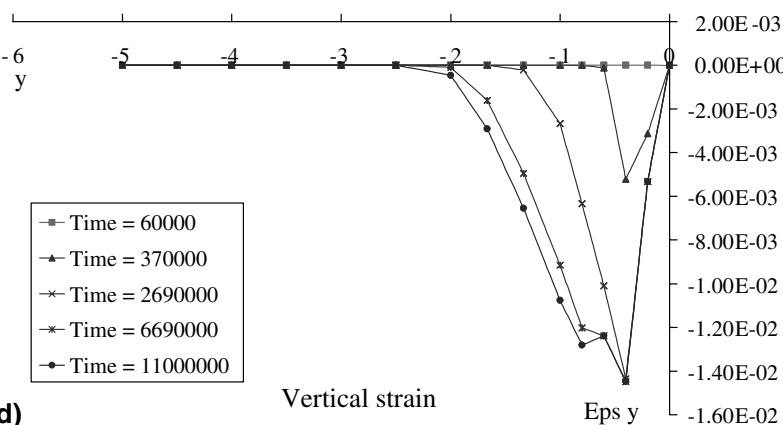

Fig. 12. The vertical strain distributions along the column for the four cases at a series of time steps.

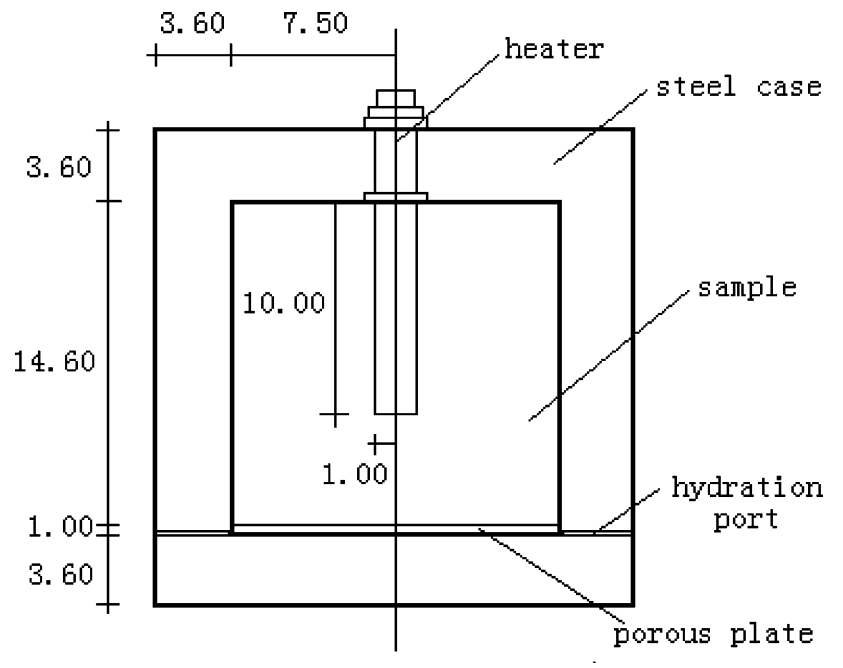

Fig. 13. The model diagram for thermo-hydro-mechanical cell (Benchmark Test 2.2) with an inserted heater (distances in $\mathrm{cm}$ ).

179 eight-node elements are used. The initial values of the parameters are listed in Table 3 . The steel case is impermeable to water. The gas pressure is assumed constant equal to atmosphere pressure during the whole process. The test is divided into the two phases. In the 1st phase, the heater temperature increases from 295 to $373 \mathrm{~K}$. Correspondingly, the water pres-
Table 3

The initial conditions

\begin{tabular}{ll}
\hline Total stress & $\sigma=0 \mathrm{~Pa}$ \\
Degree of saturation & $S_{\mathrm{r}}=0.49$ \\
Estimated pore water pressure & $p_{\mathrm{w}}=-78.5 \mathrm{MPa}$ \\
Gas pressure & $p_{a}=100 \mathrm{kPa}$ \\
Initial temperature & $T=293 \mathrm{~K}$ \\
\hline
\end{tabular}

sure at the zone near the porous plate also increases from -78.5 to $1.1 \mathrm{MPa}$. This phase lasts $10,000 \mathrm{~s}$. During the 2 nd phase (from $10,000 \mathrm{~s}$ to $2401.6 \mathrm{~h}$ ) the heater temperature remains constant. Fig. 14 illustrates the evolution of the water intake obtained by present modelling and compared with the experimental

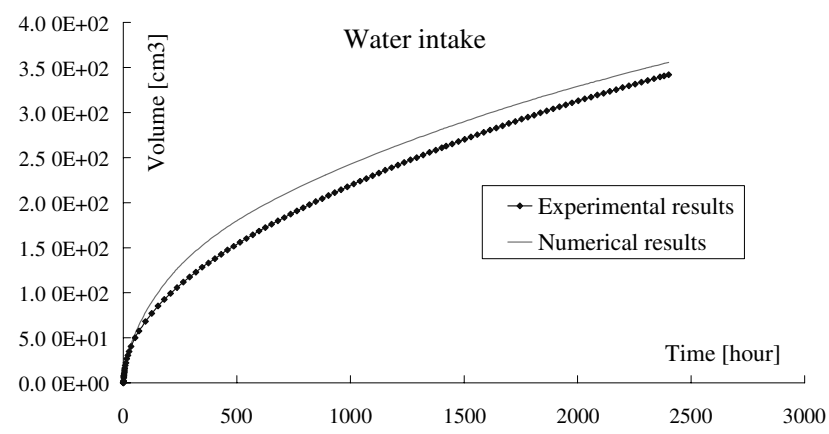

Fig. 14. Comparisons between experimental and numerical results on the water intake. 


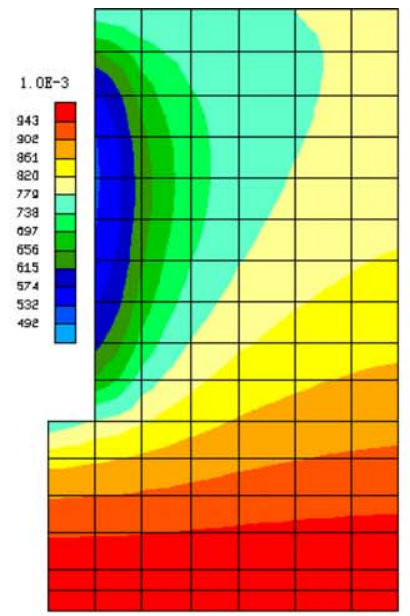

(a)

Saturation (\%)

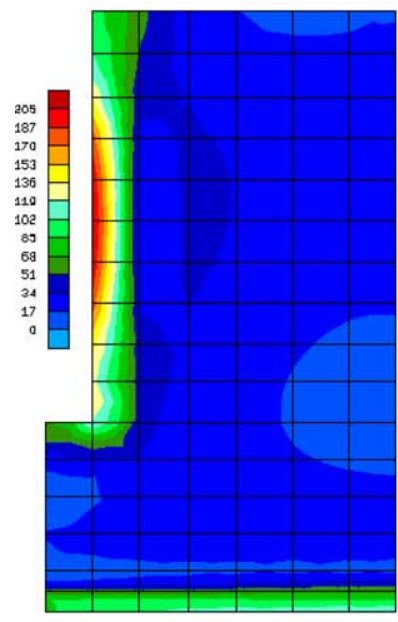

(e) Deviatoric stress $\sigma_{e q}(\mathrm{~Pa})$

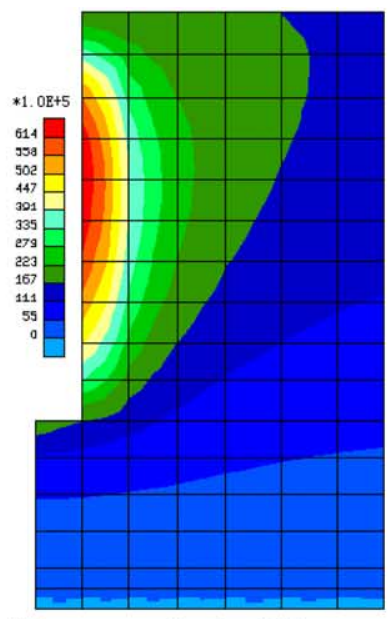

(b)

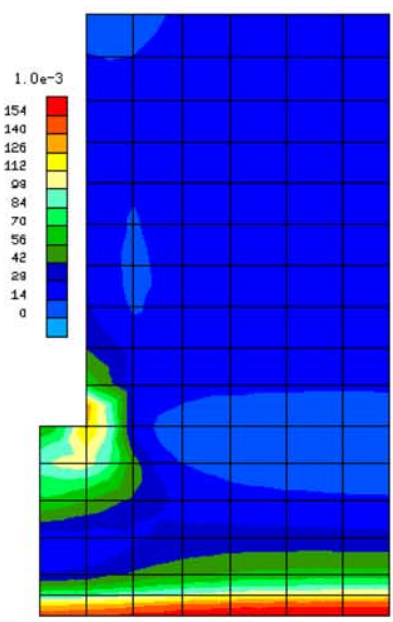

(f)

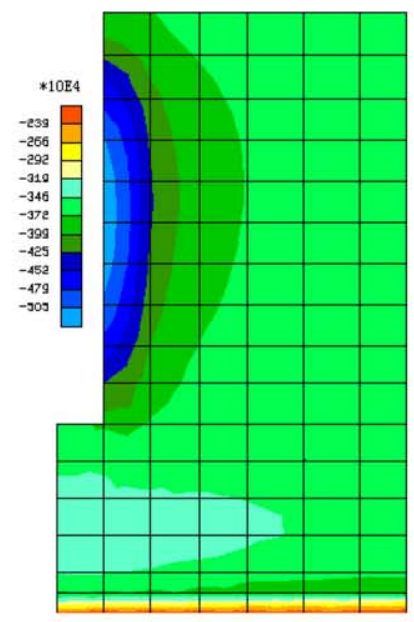

(c) Mean stress $\sigma_{m}(\mathrm{~Pa})$

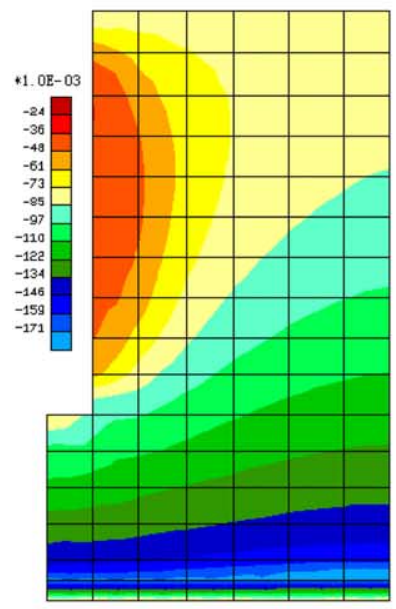

(g) Plastic volumetric strain $\varepsilon_{v}^{p}$

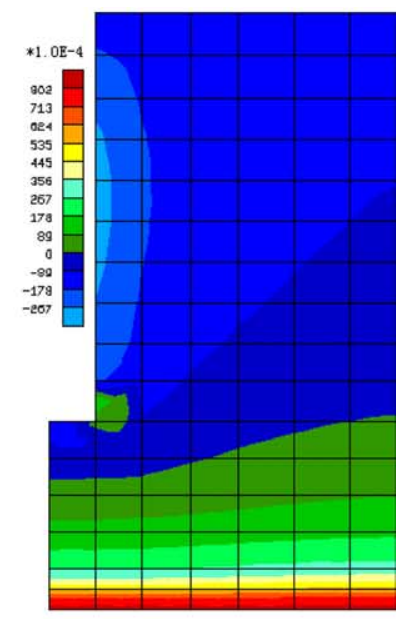

(d)

Mean strain $\varepsilon_{m}$

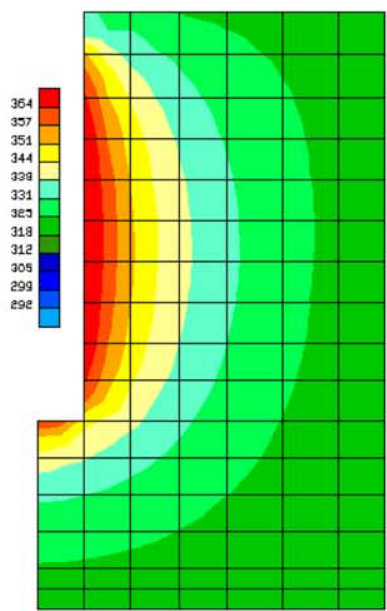

(h) Temperature $T(K)$

Fig. 15. Contours obtained by the numerical modelling of Benchmark Test 2.2 at 2401.6 h for: (a) saturation; (b) suction; (c) mean stress; (d) mean strain; (e) deviatoric stress; (f) deviatoric strain; (g) plastic volumetric strain; (h) temperature.

results. Fig. 15 illustrates the contours obtained by the numerical modelling for saturation, suction, deviatoric and mean strain/stress, plastic volumetric strain, temperature at $2401.6 \mathrm{~h}$. The main purpose of this example is to show the capability and applicability of the present model in modelling rather complicated 2D problems.

\section{Conclusion}

A thermal-hydro-mechanical constitutive model for unsaturated soils is presented in this paper. The model is based on the four component yield surfaces of the CAP model and on the experimental results obtained for different types of soils. The extension of the model to including the effect of temperature is embodied through the thermal softening and the suction variation with respect to temperature, as well as the thermal effect to the hydraulic properties. The present model has been implemented in the finite-element code LAGACOM. The comparisons of the numerical simulations with experimental results show that the thermal-hydromechanical behaviour is properly modelled in the present work.

\section{Acknowledgements}

This work is sponsored by Ministry of Education of Belgium under the international joint research project "Qualité et durabilité de la protection des nappes aquifères sous sites d'enfouissement technique avec barrières argileuses d'étanchéité" and The National Natural Science Foundation of China under the project 
Nos. 50278012, 10302005, 59878009 and 10225212. The support is greatly acknowledged.

\section{References}

[1] Hueckel T, Borsetto M. Thermoplasticity of saturated soils and shales: constitutive equations. J Geotech Eng ASCE 1990;116(12):1765-77.

[2] Hueckel T, Baldi G. Thermoplasticity of saturated clays: experimental constitutive study. J Geotech Eng ASCE 1990;116(12):1778-96.

[3] Baldi G, Hueckel T, Pellegrini R. Thermal volume changes of the mineral-water system in low-porosity clay soils. Can Geotech J 1988;25:807-25.

[4] Hueckel T, Pellegrini R, Olmo C. A constitutive study of thermoelasto-plasticity of deep carbonatic clays. Int J Numer Anal Meth Geomech 1998;22:549-74.

[5] Cui YJ, Sultan N, Delage P. A thermomechanical model for saturated clays. Can Geotech J 2000;37:607-20.

[6] Romero E, Gens A. Characterisation and thermo-hydro-mechanical behaviour of unsaturated Boom clay: an experimental study. Thesis Doctoral 1999, Technical University of Catalonia (UPC), Barcelona, Spain.

[7] Lewis RW, Majorana CE, Schrefler BA. Coupled finite element model for the consolidation of non-isothermal elastoplastic porous media. Transport Porous Media 1986;1:155-78.

[8] Ferguson WJ, Lewis RW. Fully non-linear analysis of temperature, moisture content, and pressure in a capillary porous body. Numeri Heat Transfer B 1993;23:91-110.

[9] Lewis RW, Cross JT, Gethin DT, Ransing RS, Manzari MT, Rahman NA. Recent developments in heat transfer and porous media. In: Proceedings of the International Conference on Advanced Computational Methods in Heat Transfer, June 1998. Computational Mechanics Publ.; 1998. p. 603-14.

[10] Thomas HR. The influence of non-liner thermal parameters on moisture content distributions in unsaturated soils. Int $\mathbf{J}$ Numer Meth Eng 1988;26:263-79.

[11] Thomas HR, Sansom MR. Fully coupled analysis of heat moisture and air transfer in unsaturated soil. J Eng Mech ASCE 1995;121(3):382-405.

[12] Thomas HR, He Y, Sansom MR, Li CLW. On the development of a model of the thermo-mechanical-hydraulic behaviour of unsaturated soils. Eng Geol 1996;41:197-218.

[13] Thomas HR, He Y, Onofrei C. An examination of the validation of a model of the hydro/thermo/mechanical behaviour of engineered clay barriers. Int $\mathbf{J}$ Numer Anal Meth Geomech 1998;22:49-71.

[14] Schrefler BA. F.E. in environmental engineering: coupled thermohydro-mechanical processes in porous media including pollutant transport. Arch Comput Meth Eng 1995;2:1-54.

[15] Gawin D, Schrefler BA. Thermo-hydro-mechanical analysis of partially saturated porous materials. Eng Comput 1996;13:113-43.

[16] Gawin D, Majorana CE, Schrefler BA. Numerical analysis of hygro-thermal behaviour and damage of concrete at high temperature. Mech Cohesive-Frictional Mater 1999;4:37-74.

[17] Gray H. Progress report on the consolidation of find-grained soils. In: Proceedings of the 1st International Conference on Soil
Mechanics and Foundation Engineering, Cambridge, MA; 1936. p. 138-41.

[18] Campanella RG, Mitchell JK. Influence of temperature variations on soil behaviour. J Soil Mech Foundation Eng Div, ASCE 1968;94:709-34.

[19] Habibagahi K. Temperature effect and the concept of effective void ratio. Indian Geotech J 1977;1:14-34.

[20] Tidfors M, Sallfors G. Temperature effect on preconsolidation pressure. Geotech Testing J 1989;12:93-7.

[21] Passwell RE. Temperature effects on clay soil consolidation. J Soil Mech Foundation Eng Div, ASCE 1967;93:9-22.

[22] Eriksson LG. Temperature effects on consolidation properties of sulphide clays. In: Proceedings of the 12th International Conference on Soil Mechanics and Foundation Engineering, vol. 3; 1989. p. 2087-90.

[23] Morin R, Silva AJ. The effects of high pressure and high temperature on some physical properties of ocean sediments. J Geophys Res 1984;89:511-26.

[24] Mitchell JK. Fundamentals of soil behaviour. New York: Wiley; 1993.

[25] Towhata I, Kuntiwattanakul P, Seko I, Ohishi K. Discussion on volume change of clays induced by heating as observed in consolidation tests. Soils Foundations 1995;35:124-37.

[26] Delage P, Sultan N, Cui Y. On the thermal consolidation of Boom clay. Can Geotech J 2000;37:343-54.

[27] Alonso EE, Gens A, Josa A. A constitutive model for partially saturated soils. Geotechnique 1990;40(3):405-30.

[28] Gens A, Alonso EE. A framework for the behaviour of unsaturated expansive clays. Can Geotech J 1992;29:1013-32.

[29] Gens A. Constitutive laws. In: Gens A, Jouanna P, Schrefler BA, editors. Modern issues in non-saturated soils. Berlin: Springer; 1995. p. 129-58.

[30] Modaressi A, Modaressi H. Thermoplastic constitutive model for unsaturated soils: a prospective approach. Numer Models Geomech - NUMOG V 1995:45-50.

[31] Fredlund DG, Xing A. Equation for the soil-water characteristic curve. Can Geotech J 1994;31:521-32.

[32] Hueckel T. Water-mineral interaction in hygromechanics of clays exposed to environmental loads: a mixture-theory approach. Can Geotech J 1992;29:1120-5.

[33] Gens A. Constitutive modelling of expansive soils. Unsaturated soils: Recent developments and applications. Barcelona: Civil Engineering European Courses; 1993.

[34] Schroeder C, llling P, Robert C, et al. PASACHALK: Mechanical behaviour of partially and multiphase saturated chalks fluid-skeleton interaction: main factor of chalk oil reservoirs compaction and related subsidence. Final Report 2000, Universite de Liege-LGIH, Universite de Liege-DIG, Ecol Nationale des Ponts et Chaussees-CERMES, TotalFinaElf Exploration Norge AS.

[35] Li Xikui, Fan Y, Thomas HR. Finite element method and constitutive modelling and computation for unsaturated soils. Comput Meth Appl Mech Eng 1999;169:135-59.

[36] Drucker DC, Prager W. Soil mechanics and plasticity analysis or limit design. Quart Appl Math 1952;10(2):157-65.

[37] Simo JC, Kennedy JG, Govindjee. Non-smooth multisurface plasticity and viscoplasticity. Loading/unloading conditions and numerical algorithms. Int J Numer Meth Eng 1988;26: $2161-85$. 